\title{
Some thoughts from the other side of the table, or the last presidential address
}

\author{
Norman E. Shumway, Jr, MD, $\mathrm{PhD}^{\dagger}$
}

I am just as surprised to be standing here today as you are to see me here. I just hope I will not become dumbstruck like the man who had both déjà vu and amnesia at the same time. Two years ago when the association met in New Orleans and Herb Sloan called to tell me I was to be the vice president, I had no idea that it was tantamount to being presidentelect. I thought it was like being a vice president of the American College of Surgeons or, perhaps even worse, Vice President of the United States. My confusion was compounded further by the fact none of my training was at the Johns Hopkins. This seemed almost always a prerequisite for the office. At any rate, it is a qualified pleasure to have this opportunity to reflect on three decades of experience in surgery of the heart. There have been some really great moments and some far from great. You will not be exposed in these comments to all of my prejudices but very definitely to some. First off, with apologies to Paul Ebert and his successors, the so-called presidential address should be abandoned. It is usually a summary of material already published and sometimes reveals more than we ever want to know about the incumbent. You will soon appreciate why this should be the last presidential address. It very definitely will be my last. Actually, at least two additional scientific papers could be accepted for presentation if this tradition were terminated.

Since I have no way of eluding responsibility for this year's meeting, I hope you will be interested in hearing some thoughts that have come to one of the world's great first assistants whose pleasure it has been to watch the growth and development of a talented group of colleagues. Like so many of you, I have spent considerable time across the table from young surgeons who were developing their clinical skills, giving me time to consider the so-called larger picture.

Most of you know by now that the most difficult thing about surgery - even heart surgery - is getting a chance to do it. Inthe early days at the University of Minnesota not only did the chief resident on the heart service not operate, he did not

\footnotetext{
${ }^{\dagger}$ Deceased.

Read at the 67th Annual Meeting of The American Association for Thoracic Surgery, Chicago, Illinois, April 6-8, 1987.

Address for reprints: Lawrence H. Cohn, MD, Division of Cardiac Surgery, Brigham, and Women's Hospital, 75 Francis St, Boston, MA 02115 (E-mail: lcohn@ partners.org).

J Thorac Cardiovasc Surg 2011;142:1296-8

$0022-5223 / \$ 36.00$

Copyright @ 2011 Published by Elsevier Inc. on behalf of The American Association for Thoracic Surgery

doi:10.1016/j.jtcvs.2011.06.007
}

even first assist. Eventually Owen H. Wangensteen-the celebrated chief of surgery-split the cardiovascular surgical service so that two full professors were not helping each other do the operations. I resolved then never to indulge in this kind of so-called residency training if the opportunity presented to do otherwise. Certainly it cannot matter as much who does the operation, as how it is done. The day of the super surgical technician has been greatly exaggerated. Some of you, exposed to more general surgery than I, will recall the immortal words of Sir Heneage Ogilvie who said, "when the incomparable surgical technician meets the impossible deodenum, the duodenum wins every time." Sir Heneage also remarked with respect to the great surgeon who can always get out of trouble that he would much rather fly across the Atlantic with a pilot who never had difficulty than with one who was an expert at landing on icebergs.

In 1972, several of us were fortunate enough to attend the dedication banquet for that first of a long line of heart institutes around every corner. Wherever there's a cardiologist with a balloon catheter there has to be a heart institute. At any rate, the head table that night in Houston was actually double-decked to accommodate the many after-dinner speakers. Finally, it came my turn to offer a few remarks, and it looked like a good chance to emphasize the point that how is more important than who. So, I stated that we all congratulated and envied Dr Cooley for his new institute. We in Palo Alto often see foreign visitors on their way home who have spent varying periods of time at the Texas Heart Institute that, when they leave Houston, they think only Denton Cooley can do a particular operation but, when they leave Palo Alto, they think anyone can do it. There was some muted and sparse laughter but not much recognition of the point. To continue from the other side of the table, it is easy to underline the two most important factors in the entire realm of open heart surgery and cardiopulmonary bypass: (1) water runs downhill and (2) air rises. The corollary of course is that water seeks its own level, and we all know bleeding always stops. Once the surgeon has a good grip on these principles, he or she is ready to consider the matter of cardiac protection.

There have been many fads in cardiac surgery through the years, and cardioplegia, by itself a most unattractive word, is one of them. Almost as many papers have been written about cardioplegia as use of the internal thoracic artery for coronary artery bypass grafting. Cardioplegia is in such routine use that some author recently felt compelled to write a paper telling how to do epicardial vascular surgery 
without cardioplegia. There is almost as much discussion about ingredients for the cardioplegic solution as there was in the early days regarding the constituents of the prime for the heart-lung machine. It came down almost to the use of vitamins.

In 1958, we became interested in improving the operating conditions for open heart surgery through elective arrest. Potassium infusion at the aortic root was even then in vogue with posthumous recognition being given to the 1883 observation by Sidney Ringer that potassium will stop the heart. Results were suboptimal to put it mildly probably because the component of hypothermia was not present. The heart would stop certainly, but getting it started again became the problem. The surgeon could finally see what he was doing to be sure. All too often the pathologist saw it also. Certainly, the concentration of potassium was excessive. Not much thought was required to wonder if hypothermia might protect against the frequently irreversible nature of potassium-induced cardiac arrest.

Out of this background developed the concept of local hypothermia. The heart, unlike the liver or kidneys, is a shell and not a solid organ. In the definitive experiment of orthotopic cardiac transplantation, Dr Richard R. Lower found up to 7 hours of anoxia were tolerated through simple immersion of the donor heart in physiological saline at 2 to $4^{\circ} \mathrm{C}$. Local or topical hypothermia for protection of the anoxic heart was immediately adopted for clinical use. Having never administered crystalline or blood cardioplegia, I continue to be amused by the extravagant claims for it vis-à-vis improved operative results.

Last month at the annual meeting of the American College of Cardiology, I discussed in detail the results of heart transplantation. The fact that 1 -year survival now stands at $80 \%$ and 5 -year survival at $60 \%$ is generally accepted and appears reproducible in many centers. Today, however, I would like to direct your attention to the other side of the picture: A tale of two donors.

Our first little story goes back to 1973 , about the time Philip Caves introduced percutaneous transvenous endomyocardial biopsy for the diagnosis of cardiac rejection. For reasons that no one could understand, the Stanford Hospital administrators had entered into an agreement with the Santa Clara County coroner not to utilize donors who were homicide victims. On the 13th of September, 1973, the Alameda County district attorney called to offer such a heart donor on behalf of the victim's next of kin. Because of the agreement with the coroner, it was not possible to move the body to Stanford. Oakland is about 50 air miles from Palo Alto, so we decided to remove the heart at Highland Hospitalout of the Santa Clara County coroner's jurisdiction-and fly it by helicopter to Stanford. Appropriate plans were made and the transplant uneventfully completed. A past president of this society, Dr Paul C. Samson, was in attendance when we removed the donor heart; he said with total wonderment, "where are you going with that?" Perhaps predictably the defendant's attorney went to court, and a jury trial was convened several months later to test the principle of brain death. The defense contended that the gunshot victim was doing very well until those surgeons from Stanford removed his heart. Even our neurosurgeon, whose reactionary nature was little help in the early days of heart transplantation, eventually testified concerning the criteria for brain death. By then the Harvard panel had already convened, and bases for the diagnosis of brain death were well publicized. The judge instructed the jury that the definition of death had been fully respected, and when the verdict was read, the state of California had its judicial precedent for the legislature to redefine death in terms of cerebral function. The above donor episode inaugurated distant or remote heart procurement and today less than $5 \%$ of all hearts transplanted at Stanford are from on-site donors. The necessary legal precedent for statutory recognition of brain death in the state of California was thus established.

We now move to a second donor story, which has significant scientific overtones particularly with reference to the subject of cardiac preservation. Three days before last Christmas, we were notified of a 4-month-old heart donor in Fargo, North Dakota. The blood type and weight were perfect for a 5-month-old recipient dying of endocardial fibroelastosis. Despite the projected anoxic time of 4 to 5 hours, we decided to go ahead considering the paucity of infant donors. Dr Edward Stinson accompanied the procurement team since an expert opinion was required concerning function of the donor heart. A large Lear jet was chartered to make the 2000 mile trip, and a party of 6 led by Dr Stinson embarked for the frozen tundra of North Dakota. The team carried its usual surgical instruments and was clad only in scrub suits and white coats. The trip to Fargo was uneventful, and the baby donor heart was found to be functionally satisfactory. After a team from the University of Minnesota had taken the liver, Stinson removed the heart, placed it in cold storage, and proceeded quickly to the waiting aircraft. To the consternation and frustration of all, one of the jet engines would not start, and valuable time was lost while giant hair dryers were used in an effort to windmill the disabled fan jet into action. Nothing happened even when a lighted broom was thrust into the mouth of the jet engine.

The Stanford contingent deplaned and requested an audience with the colonel who was in charge of North Dakota's Air National Guard. It would be great if a supersonic military jet could fly the heart to Palo Alto. The colonel explained that his mission was to protect the north central United States from a surprise attack over the pole. After all, the Russians could be coming almost any time. As a matter of fact, you will remember they were in New York last year for this very meeting as guests of our president, Jim Malm. They appeared quite peaceful as long as there was an adequate supply of vodka. 
The only chance now lay in getting the governor of North Dakota to overrule the colonel and release a military jet for the trip back to Stanford. It was now 2:15 AM, Central Standard Time, and the heart had been in extracorporeal residence for 2-and-a-half hours. To make the proverbial long story short, the governor, George Sinner, gave the order for an F-4 phantom jet to be available. Incidentally, Governor Sinner has a brother who is a parish priest in Fargo and, of course, he bares the unlikely and seemingly contradictory name of Father Sinner. The F-4 phantom is a 2-passenger supersonic jet with a range of about 1000 miles. There is room for the pilot and a navigator or weapons officer but no other storage that is both temperature and pressure controlled. The navigator would have to hold the ice chest containing the donor heart on his lap. "Just a minute," replied the navigator, "if I have to eject, that ice chest will go right through me." "No, thank you," decided the navigator. The ice chest was then lashed to the seat vacated by the navigator, and the pilot became a latter-day lone eagle with a brief but obligatory refueling stop at Ogden, Utah.

Undaunted by all of these problems and complications, the implant team started the recipient procedure at 4:45 Pacific Standard Time. At 5:30 Am, the new heart was in place, and the anoxic period had extended to just 15 minutes short of 8 hours. Richard Lower's experimental work of 1962 had reached clinical affirmation. The 5-month-old recipient was discharged 3 weeks later and continues to do well.

Dr Stinson and his exhausted comrades were stranded in North Dakota and beginning to resemble the ill-fated Donner party. They finally made it back to San Francisco by commercial aircraft but not without attracting considerable suspicion as they changed planes in the Denver airport. For all I know the Lear jet may still be on an isolated runway in the frozen north.

So, we see the transplant surgeons and physicians get the glory, the transplant recipients gain the benefits, but the transplant donors also have their moments in medical history. In the two incidents I have cited an important state law was formulated with the advent of distant heart procurement, and a heretofore seemingly unattainable period of cardiac preservation, nearly 8 hours, was clinically successful.

Before I go let me introduce several of my colleagues who are now or who have been at Stanford and have propelled the art and science of heart transplantation into a therapeutic reality.
First, Dr Richard R. Lower is the professor and chief of cardiovascular surgery at the Medical College of Virginia in Richmond. Long-term survival of the orthotopic heart transplant was achieved in the laboratory by Dr Lower in 1965 thus providing the necessary background for the clinical effort.

Dr Edward B. Stinson is the Doelger Professor of Cardiovascular Surgery at Stanford. A man for all seasons, immunologist, infectious disease expert, and cardiac surgeon extraordinaire, Dr Stinson has been in charge of the heart transplant program at Stanford for the past 15 years.

Dr Randall B. Griepp is professor and chief of cardiovascular surgery at the Mount Sinai Medical Center in New York City. Dr Griepp is presently on parole having been charged with committing a successful heart transplant without first gaining permission from the New York City administrators. Most of us think there is room for a second heart transplant center in the state of New York since there must be at least 90 hospitals trying to do heart transplants in less populated states.

Mr Philip K. Caves was the former Regius Professor of Cardiovascular Surgery at the University of Glasgow, Scotland. His untimely death in 1976 deprived him of full recognition for inventing percutaneous transvenous endomyocardial biopsy without which there could be no cyclosporine era.

Dr Margaret E. Billingham is professor of pathology at Stanford and world authority on matters of the heart. She and professor Caves made cardiac biopsy the gold standard for the diagnosis of immunologic events surrounding heart and heart-lung transplantation.

Dr Philip E. Oyer is professor of cardiovascular surgery at Stanford, and co-investigator of the successful Novacor left ventricular assist device. Dr Oyer also holds a $\mathrm{PhD}$ in biochemistry, and his expertise in many related areas has contributed much to the science of transplantation. Oyer was instrumental in gaining for Stanford the use of cyclosporine a beginning in December 1980.

Dr Bruce A. Reitz, professor and chief of cardiac surgery at the Johns Hopkins and who, after conducting meticulous animal experiments, performed the first successful clinical transplant of the heart along with both lungs.

If this material, to which you have listened most admirably, does not qualify for the last presidential address, you all have sufficient tolerance to accept even a xenograft!

Thank you. 